\title{
PETROLOGIA DE GNAISSES ALCALINOS DA SERRA DA MANTIQUEIRA EM MINAS GERAIS, BRASIL
}

\author{
C.P.Pinto
}

Gnaisses alcalinos ocorrem em três corpos principais (Ubari, Mercês e Matola) e em diversos outros corpos menores, ao longo de uma faixa com cerca de $120 \mathrm{~km} \mathrm{x} 15$ $\mathrm{km}$, entre as localidades de Matola (W) e Ubari (E), na serra da Mantiqueira, em Minas Gerais. Ocupam uma provável zona de descontinuidade entre blocos crustais. Nesta mesma faixa ocorrem granulitos toleíticos e cálcio-alcalinos e granitóides cálcio-alcalinos.

O maciço de Ubari foi descrito pela primeira vez por Brandalise et al.(1976). O maciço de Mercês foi identificado pelo geólogo Euler Miranda Bruno (Brandalise \& Viana, 1993). O maciço de Matola foi reconhecido por Ebert (1956).

Maciço de Ubari - as rochas dominantes são gnaisses sieniticos e quartzo sieníticos, com tipos ricos em máficos e tipos graníticos subordinados. Enclaves (autólitos) máficos e diques sieníticos indeformados foram identificados. $\mathbf{O}$ tipo petrográfico principal é um ortoclásio metassienito rosado, de grãos médios, com estrutura variando de quase homófana a laminada. Localmente mostra-se bandado, com leitos ricos em máficos constituídos principalmente por anfibólios e piroxênios cálcio-sódicos, identificados ao microscópio como hornblenda, riebeckita, tremolita, aegirina e hiperstênio, em proporções variadas, sendo comum a biotita.

Em termos petrográficos, os maciços têm as seguintes características:

Maciço de Mercês - as rochas dominantes são gnaisses sieníticos, com tipos mais ricos em quartzo subordinados. Os máficos foram identificados ao microscópio petrográfico como riebeckita, hornblenda, aegirina-augita, diopsídio e rara biotita. Titanita pode estar presente, atingindo até $5 \%$ em volume. São rochas cinza rosadas, foliadas a bandadas, de grãos finos a médios, com porções granito-pegmatóides sugerindo processo de fusão.

Maciço de Matola - as rochas dominantes são gnaisses sieníticos, caracterizados principalmente pela abundância de feldspato potássico. Alguns domínios são ricos em quartzo. São rochas predominantemente claras, de tonalidade rosa, com leitos mais ricos em máficos a semelhança de rosários de grãos de piroxênio (aegirina-augita) e anfibólio (hastingsita?), identificados ao microscópio. Titanita é um constituinte importante e a biotita está ausente.

Os dados químicos em rocha total foram obtidos por Pinto $(1991,1995)$, Viana (1991) e Brandalise \& Viana (1993). As rochas de Matola têm um comportamento geoquímico distinto das demais.

Em diagrama petroquímico de nomenclatura são adamelito, quartzo sienito, sienito, quartzo monzonito e monzonito. As rochas de Matola são adamelito e quartzo sienito. Todas mostram trend de diferenciação segundo as séries magmáticas alcalina-aluminosa $\mathrm{e}$ alcalina-supersaturada, são metaluminosas, com razão de alcalinidade $\mathrm{K}_{2} \mathrm{O} / \mathrm{Na}_{2} \mathrm{O}>1$.

Companhia de Pesquisa de Recursos Minerais, Serviço Geológico do Brasil, SUREG/BH. 
À exceção das rochas do Maciço de Matola, as demais apresentam padrão de ETR altamente fracionado, concentração total variável e elevada (até $2233 \mathrm{ppm}$ ), anomalias negativas de $\mathrm{Eu}(0,65<\mathrm{Eu} * / \mathrm{Eu}<0,75)$ e inclinação constante das curvas entre o $\mathrm{La} \mathrm{e} \mathrm{Lu}$. Com base na similaridade das curvas de ETR, que se refletem nas razões $\mathrm{La}_{n} / \mathrm{Lu}_{\mathrm{n}}$, estabelecem-se três associações litológicas, comparáveis aos padrões dos ortognaisses sieníticos das serras de Itiuba Poço de Fora (Figueiredo, 1981), de Itiuba, Santanápolis e São Félix (Conceição, 1993a, b) e dos gnaisses hiperstênio monzoníticos de Água Sumida (Silva, 1991), todos na Bahia.

As rochas de Matola mostram dois padrões distintos de ETR. Os parâmetros químicos são variáveis, com razões $\mathrm{La}_{n} / \mathrm{Lu}_{\mathrm{n}}$ de 4,47 e 10,44 (padrão menos fracionado) e 8,96 e 31,66 (padrão mais fracionado). 0 somatório de ETR é inferior ao do grupo anterior, não ultrapassando $395 \mathrm{ppm}$. $\mathrm{O}$ grupo menos fracionado apresenta forte anomalia negativa de Eu $(\sim 0,5)$, que tende a se anular no outro grupo $(0,84$ e 1,04$)$.

Normalizadas ao padrão ORG mostram pronunciado enriquecimento em $\mathrm{Ba}$, $\mathrm{Rb}$, Sr e K e também um característico enriquecimento em $\mathrm{Ce}$ e $\mathrm{Sm}$ em relação a $\mathrm{Nb}$ e $\mathrm{Zr}$, além de depleção em Y e Yb. As rochas de Matola mostram um comportamento ligeiramente diferente por apresentarem menores concentrações de $\mathrm{Ce}$ e $\mathrm{Sm}$ (até inferiores ao padrão ORG) e enriquecimento em Y.

O metamorfismo atingiu a fáceis anfibolito, com retrometamorfismo na fácies xisto verde. A deformação é heterogênea, com zonas fortemente cisalhadas em regime dúctil, outras com texturas ígneas preservadas.

Os dados petrográficos, mineralógicos e químicos deixam claro o caráter alcalino destas rochas, com teores de $\mathrm{SiO}_{2}$ variando entre $46,2 \%$ a $70,3 \%$, com diferenças de até $15 \%$ em um mesmo corpo. São observados, também, altos teores de $\mathrm{K}_{2} \mathrm{O}+\mathrm{Na}_{2} \mathrm{O}, \mathrm{F}, \mathrm{Ba}, \mathrm{Sr}$ e ETR (exceto em Matola) e, em parte, de $\mathrm{Zr}$ e Y. Os teores de $\mathrm{Nb}$ são baixos, em geral inferiores a 20 $\mathrm{ppm}$. Os teores de $\mathrm{CaO}$ e $\mathrm{MgO}$ são altamente variáveis, em geral decrescendo com o incremento em $\mathrm{SiO}_{2}$; os maiores valores correspondem às rochas com altas concentrações de máficos. 0 flúor variou entre 370 e $4600 \mathrm{ppm}$, bastante superior ao $\mathrm{Cl}$, geralmente inferior a $100 \mathrm{ppm}$. 0 comportamento químico destas rochas, para valores de $\mathrm{SiO}_{2} \cong 70 \%$, é perfeitamente compativel com granitos tipo-A mostrados por Eby (1990), ressaltando-se um enriquecimento em $\mathrm{Ba}$ e Sr e empobrecimento em $\mathrm{Nb}$ nas rochas deste estudo.

Esse autor sintetiza a origem das suites graníticas tipo-A como relacionada a: 1) fracionamento de um magma basáltico produzindo diferenciados ricos em álcalis; 2) soluções de estágios tardios ricos em álcalis, $\mathrm{F} \mathrm{e} \mathrm{Cl}$, interagindo com o magma residual ou metassomaticamente com granitos pré-existentes; 3) fusão de rochas metamórficas félsicas de alto grau, da qual uma fase fundida prévia foi extraída; 4) fusão parcial de eclogito e granada peridotito a profundidade mantélica; 5) fusão parcial incongruente de biotita, na presença de vapor, a partir de fonte metapelitica. Cotejando-se os dados químicos, principalmente de ETR, F e $\mathrm{Cl}$ do maciço de Matola com os modelos petrogenéticos, propõe-se para os ortognaisses alcalinos deste maciço um protólito de fonte crustal metatonalítica ou granulítica gerado por fusão parcial anidra na presença de voláteis $(\mathrm{F} \mathrm{e} \mathrm{Cl})$, com possivel participação de hornblenda e diferenciação de cumulados plagioclásicos em ambiente crustal continental. $\mathbf{O}$ padrão das curvas de ETR sugere que estas rochas não são comagmáticas às dos outros maciços.

Para os outros maciços advoga-se origens a partir de fonte basáltica mantélica previamente enriquecida em elementos incompativeis (altas concentrações de $\mathrm{Ba}, \mathrm{Sr}, \mathrm{K}$ e ETR), que sofreria fracionamento envolvendo plagioclásio (anomalias negativas de Eu). $\mathbf{O}$ padrão de ETR fortemente fracionado e enriquecido em ETRL, as anomalias negativas de Eu e o paralelismo das curvas são próprios de processos primários, reforçando esta hipótese.

Concluindo, dentre os diversos ambientes geotectônicos possiveis para a acomodação de suites alcalinas, os dados apontaram para anorogênio do tipo soerguimento 
epirogênico ou rifte intraplaca continental. Uma possibilidade alternativa seria um ambiente póscolisional, relacionado a zonas transcorrentes. Os dados ainda são insuficientes para uma distinção, uma vez que as rochas desses ambientes têm composições químicas similares. Estas rochas estariam marcando o provável limite entre as Provincias Geotectônicas o São Francisco e Mantiqueira. Para elucidar a questão, são recomendáveis estudos de detalhe em cada maciço, incluindo petrografia, química mineral, geocronologia, geotermobarometria, análise estrutural e geofisica. Deve ser testada, também, a relação destas rochas com as zonas transcorrentes da Cunha de Guaxupé.

\section{Referências Bibliográficas}

BRANDALISE, L.A.; VIANA, H.S. (1993) Programa Levantamentos Geológicos Básicos do Brasil. Folha Rio Pomba SF.23-X-D-I. Estado de Minas Gerais. Escala 1:100.000. Belo Horizonte, DNPM/CPRM.

BRANDALISE, L.A.; RIBEIRO, J.H.; FERRARI, P.G. (1976) Projeto Vale do Paraíba do Sul. Belo Horizonte, DNPM/CPRM, 411p. (Relatório Téc. DGM n.2595).

CONCEIÇÃO, H. (1993a). Petrology of the syenites from the Salvador-Curaçá Mobile Belt (Bahia-Brazil): Geodynamic Significance. Anais da Academia Brasileira de Ciências. Suplemento, v. 65 , n.1, p.17-32.

CONCEIÇÃO, H. (1993b) Petrology of the syenites from the Salvador-Curaçá Mobile Belt (Bahia-Brazil) In: WORKSHOP MAGMATISMO GRANÍTICO E MINERALIZAÇÕES ASSOCIADAS (MAGMA), Rio de Janeiro, 1993. Resumos Expandidos, Roteiro de Excursão e Programas. Recife, UFPE. p.1-12.

EBERT, H. (1956) Seção de Petrografia. Relatório Anual do Diretor, Divisão de Geologia e Mineralogia, v.1956, p.97-107.

EBY, G.N. (1990) The A-type granitoids: A review of their occurrence and chemical characteristics and speculations of their petrogenesis. Lithos, v.26, p.115-134.

FIGUEIREDO, M.C.H. (1981) Geoquímica das rochas metamórficas de alto grau do nordeste da Bahia - Brasil. In: INDA, H.A.V.; MARINHO, M.M.; DUARTE, F.B. (Eds.). Geologia e Recursos Minerais do Estado da Bahia: textos básicos. Salvador. SMG/CPM, v.4, p.171.

PINTO, C.P.; PADILHA, A.V. (1993) Esboço de integração geológica regional e evolução tectônica para parte da região sudeste do Brasil. In: SIMPÓSIO DE GEOLOGIA DE MINAS GERAIS, 7., Belo Horizonte, 1993. Anais. Belo Horizonte, SBG/MG. p.65-68. (Boletim, 12)

PINTO, C.P. (1991) Programa Levantamentos Geológicos Básicos do Brasil. Folha Lima Duarte, SF 23-X-C-VI. Estado de Minas Gerais. Escala 1:100.000 Belo Horizonte, DNPM/CPRM.

PINTO, C.P.; BRANDALISE, L.A.; VIANA, H.S.; BRUNO, E.M. (1992) Suíte Metamórfica São Bento dos Torres, Serra da Mantiqueira, MG. REM. Revista da Escola de Minas. Escola Federal de Minas de Ouro Preto. v.45, p.187-190.

SILVA, L.C. (1991) Geoquímica, petrologia e evolução dos granulitos depletados e não depletados da Bahia. Brasilia, 143p. (Dissertação - Mestrado) - Instituto de Geociências, Universidade de Brasilia.

VIANA, H.S. (1991) Programa levantamentos geológicos básicos do Brasil. Folha Barbacena SF. 23-X-C-III. Estado de Minas Gerais. Escala 1:100.000. Belo Horizonte, DNPM/CPRM. 